\author{
Bram Cadsby, Ninghua Du, Fei Song, and Lan Yao
}

Department of Economics and Finance

University of Guelph

Discussion Paper 2014-05 


\title{
PROMISE KEEPING, RELATIONAL CLOSENESS, AND IDENTIFIABILITY: AN EXPERIMENTAL INVESTIGATION IN CHINA
}

\author{
Bram Cadsby, University of Guelph. \\ Ninghua Du, Shanghai University of Finance and Economics. \\ Fei Song*, Ryerson University. \\ Lan Yao, Shanghai University of Finance and Economics.
}

\begin{abstract}
We experimentally investigate a new variant of the trust/investment game that captures some key features of internet peer-to-peer (P2P) lending: the borrower specifies the amount of money required and makes a contingent promise about the value of the generally higher repayment prior to the investor's decision to lend the required sum or not. We examine the role played by two factors related to traditional Chinese culture and ethics: whether (i) relational closeness between the actors and (ii) the ability of the actors to observe each other's identity after the repayment decision (identifiability) affect the borrowers' decisions to make the promised repayments and ultimately the consequent aggregate realized social benefits. Using a two-by-two factorial design, we conduct four treatments in China where these factors are hypothesized to be especially salient, and also perform the identifiability treatment in New Zealand as a cultural control. We find that in China both manipulations are positively and significantly related to the probability of a repayment promise being kept. Moreover, these two factors are substitutes for each other. In New Zealand, there was no significant identifiability effect on promise keeping. The effectiveness of identifiability in China but not in New Zealand resulted in a significantly higher proportion of promises being kept when agents were identifiable in China than in New Zealand. Over time, relational closeness and identifiability both led investors in China to accept more proposals, resulting in more investment and the creation of greater social surplus.
\end{abstract}

Keywords: Promise-keeping, P2P lending, relational closeness, identifiability, China, guanxi, mianzi, business ethics, experimental.

* Corresponding Author. Ted Rogers School of Management, Ryerson University, Toronto, Ontario, Canada, M5G 2C5. Email: fsong @ryerson.ca. Tel: 1-416-979 5000, ext. 7503. Fax: 1416-979 5244. The alphabetical ordering of the authors denotes equal co-authorship. 


\section{PROMISE KEEPING, RELATIONAL CLOSENESS, AND IDENTIFIABILITY: AN EXPERIMENTAL INVESTIGATION IN CHINA}

\section{Introduction}

Many small firms have no or limited access to formal financial services. A recent report from CreditEase shows that only $30 \%$ of small firms in China apply for bank loans, and of those only 15\% actually get the loans (CreditEase, 2011). Thus, informal networks such as internet peer-to-peer ( $\mathrm{P} 2 \mathrm{P})$ lending have become important providers of credit in the past decade. As reported by Chinanews, there were more than 500 microfinance websites and more than 25 billion RMB worth of internet loans in mainland China by the end of June 2013 (Chinanews, 2013). The standard internet lending procedure is as follows. A small firm (or an individual borrower) briefly describes the project on the web and specifies the amount of money required, the promised interest rate, as well as the date of repayment. After examining the information, private investors and/or lenders (we will use the terminology investors throughout the paper) decide whether to invest in the project. In theory, a borrower's promise to repay a loan can be enforced by formal contracts and sanctioning systems. In practice, however, imperfect monitoring, information asymmetries, moral hazard, and transaction costs often make the enforcement of binding contracts infeasible or prohibitively costly. According to Chinanews, several microfinance websites have gone bankrupt since a substantial proportion of borrowers did not repay as promised (Chinanews, 2013). For example, allwinsz.cn registered in April 2013 went bankrupt in August 2013 with 100 million RMB in bad debts. ${ }^{1}$ Both financing from private investors and the honoring of promises to repay those investors are essential to realize potential gains: without investment beneficial social exchanges could not begin and without the promised repayments they would not continue.

The ethic of "promise keeping" has generally been regarded as one of the most important

\footnotetext{
${ }^{1}$ Examples of existing P2P lending websites in China include Lufax.com, renrendai.com and yirendai.com. The leading P2P website in the UK is www.zopa.co.uk. In the USA, www.proposer.com and www.lendingclub.com have grown quickly. In New Zealand, examples include www.lendit.co.nz.
} 
ethical norms governing behavior in business practice (e.g., Oakley \& Lynch, 2000 and the literature review contained therein). Gert (1998) identified promise keeping as one of the ten universal moral rules spanning all societies. However, a recent empirical investigation using US participants and a rating scenario suggests that keeping promises is actually not a high priority in a business context (Oakley \& Lynch, 2000). Oakley and Lynch (2000) did find that promise keeping was enhanced when participants were told that the promise was legally enforceable. They also examined whether or not there was a link between promise keeping and a number of demographic factors i.e., age, gender, religious beliefs, and supervisory experience. Only age proved to be significant with younger people placing a higher priority on keeping a promise.

In this paper we study two interpersonal, relational factors that potentially affect whether or not borrowers honor promises to meet their debt obligations in China. First, social ties are particularly salient in Chinese society. Moreover, in a traditionally collective society such as China the obligation of reciprocity permeates many facets of life, and is closely intertwined with the social ties or relational closeness between people involved in a transaction (e.g., Song et al., 2012). Keeping a promise to repay borrowed money with either interest or a share of profits is an example of such a reciprocity obligation. Thus China is an ideal setting in which to examine the influence of relational closeness on the role played by unenforceable contingent promises to repay borrowed funds on surplus-creating economic transactions. We ground our research in the indigenous Chinese folk psychology of guanxi. The term guanxi literally means relationship, and refers to particularistic ties rooted in a common background and experiences that facilitate exchange (Tsui \& Farh, 1997).

Second, mianzi (face) is also a salient feature of Chinese society. In Chinese culture, a person's reputation and social standing rest on maintaining or gaining mianzi, which is somewhat associated with the Western concepts of dignity, respect and social image concerns (e.g. Shutte and Thoma, 2014). According to Qi (2011), mianzi defines one's place in his/her social network. Maintaining or gaining mianzi requires ones actions to be observed by others. Given that 
keeping/breaking a promise is universally a desirable /undesirable act, we anticipate that the extent to which one's decision is observable or identifiable as emanating from a particular person will have a positive effect on the likelihood of a promise being kept.

A key methodological challenge in investigating promise-keeping behavior is the difficulty of obtaining reliable data in a naturally occurring environment. While there are published figures on the general incidence of financial fraud and other business misconduct, which may be related to the breaching of promises, the reliability of these figures is questionable because of the unwillingness to report and the difficulty of uncovering such offenses. Moreover, such aggregate data provide little information on the circumstances that led to such misconduct. Currently, much of the research on business ethics relies heavily on self-reports based on the questionnaire survey methodology. This raises a number of important methodological concerns such as social-desirability and self-presentation bias, selection issues related to participation and response rates, and memory/cognitive issues. A laboratory environment, while unable to eliminate all of these problems, offers several unique methodological advantages, all related to exerting control over the decision-making/behavioral environment. First, by holding constant factors that might affect variables of interest, we effectively minimize the influence of such confounding factors that can be extremely difficult to isolate in the field. Second, we place participants in a real economic/social situation with the adoption of salient financial incentives and social cues in order to simultaneously establish both internal validity of the experiment and the generalizability of the experimental results.

In this study we investigate experimentally a new variant of the trust/investment game (Berg et al., 1995) that captures the key features of internet P2P lending: the borrower proposes the amount of money needed and promises repayment prior to the investor's binary decision to invest or not. In our experiment, we set up a two-by-two design to examine whether the level of relational closeness (with a classmate versus stranger manipulation) and identifiability (with an identifiable player vs. an anonymous player manipulation) affect the terms of the proposal made 
by the potential borrower, the borrower's decision to make the promised repayments, the investor's decision to accept the borrower' proposal, and the consequent realized aggregate social benefits.

We conducted all four treatments at Zhejiang University in Hangzhou, China. We find that in our Chinese data there are both significant relational-closeness and identifiability effects, and that these two experimental factors are substitutes for each other: people keep promises in anonymous transactions with classmates, and they keep promises to an identifiable stranger who can also identify them. However, contrary to our expectations, when people interact with an identifiable classmate who can also identify them, the level of promise-keeping is not significantly different from either the anonymous-classmate or the identifiable-stranger treatment.

We also conducted the two stranger treatments, manipulating identifiability versus anonymity, at the University of Canterbury in Christchurch, New Zealand, to explore whether culture moderates the identifiability effect on promise-keeping. There is no significant difference in promise keeping between anonymous strangers in New Zealand and anonymous strangers in China. However, in contrast to China, there is no significant identifiability effect on the proportion of promises kept in New Zealand. This results in a significantly higher proportion of promises being kept when investors and borrowers can be identified subsequent to the repayment decision in China, where identifiability based on social image concerns (mianzi) proves to be an important factor, than in New Zealand, where it apparently is not.

Unfortunately, we could not run parallel classmate versus non-classmate sessions in New Zealand to act as a cultural control for relational closeness. This is because classes are organized differently in China than in New Zealand. In many Chinese universities, classmates take almost all of their courses together, and often live together in the same room or adjacent rooms within the same dorm. This was true at Zhejiang University, the site of the experiment in China. Being classmates is a basis for guanxi or relational closeness (Jacobs, 1979), or more specifically shouren guanxi, a particularly close category of guanxi that also includes relatives other than 
immediate family, friends, teachers, neighbors, and co-workers (Su \& Littlefield, 2001).

Although two unacquainted students from different classes might share some guanxi by virtue of attending the same university, the level of such relational closeness would be considerably lower than between two classmates (Jacobs, 1979). In particular, their relationship would be in the more distant guanxi category of shengren guanxi (Su \& Littlefield, 2001), comparable to employees in the same large company. Since there is no analogous classmate relationship at New Zealand universities, we could not run classmate treatments as cultural controls there.

The rest of the paper is organized as follows. Section 2 offers a review of the related experimental literature, while section 3 presents the details of our experimental design. We present our results in section 4, and provide some discussion and conclusions in section 5.

\section{Related Literature and Hypotheses}

A literature encompassing both psychology and economics documents the impact of preplay communication, especially in the form of promises, on subsequent levels of cooperation and other pro-social behaviors in experimental games (e.g., Bicchieri \& Lev-On, 2007, Ellinsen \& Johannesson, 2004, Ostrom et al., 1992, Sally, 1995). Charness and Dufwenberg (2006) is particularly relevant. Employing a variant of a binary trust game, they underscore the impact of communication on trust and cooperation when actions can be hidden, leading to moral hazard. ${ }^{2}$ The authors argue that the observed promise-driven behavior is consistent with "guilt aversion" i.e., people striving to live up to others' expectations, which are premised on the promise given, so as to avoid guilt. This implies that promises may influence motivation and behavior by influencing beliefs about the beliefs of others. With a mini-dictator game, Vanberg (2008) furthers this line of research and provides an example in which the effects of promises cannot be accounted for by changes in expectations, suggesting that people have a preference for promise

\footnotetext{
${ }^{2}$ The original trust or investment game was developed by Berg et al. (1995). The game involves two players. The first mover decides how much of his/her initial endowment to send to the second mover. The amount sent is multiplied by a constant greater than one to create surplus, representing the surplus created in real-world transactions by trust. The second-mover then decides how much to send back to the first mover. Camerer (2003), Chaudhuri (2009), and Johnson and Mislin (2013) all provide a good discussion about the trust game and how it has been used in experimental economics.
} 
keeping per se. Both Charness and Dufwenberg (2006) and Vanberg (2008) implement free-form communication. Bracht and Feltovich (2009) and Charness and Dufwenberg (2010) find that socalled "bare" promises have little trust-enhancing effect and a marginally significant trustworthiness-enhancing effect in binary trust games. ${ }^{3}$

A more recent paper by Charness and colleagues (2013) studies bare promises in the context of a gift exchange game, a variant of the trust game in which it is the second mover's rather than the first mover's decision that creates surplus. They implement four treatments in their two by two experimental design by varying: (1) who (the first-mover trustor or the second-mover trustee) proposes the binding amount to be sent by the trustor and (2) whether the proposal includes a nonbinding promise specifying a final allocation between the two players. Their key finding is that when it is the second-mover trustee who proposes the amount to be sent by the first-mover trustor, and the proposal includes a non-binding promise specifying a final allocation of earnings, the aggregate earnings of the two players are the highest among the four treatments.

This scenario corresponds to the peer-to-peer lending market insofar as it is the borrower who sets the terms of the transaction. However, the correspondence is not perfect. This is because in the gift-exchange setting the surplus is created by the second-mover trustee (usually thought of as an employee) through his/her selection of an "effort" level (usually not a real effort level, but rather a choice from a menu with monetary implications for each of the two players) that produces more benefit for the first-mover trustor (usually thought of as an employer) than cost for the second-mover trustee. In contrast, our focus is on a setting in which it is the investor (analogous to the first-mover trustor) who creates the surplus by providing the funds requested by a borrower (analogous to the second-mover trustee) through acceptance of the borrower's request and related contingent repayment promise. The borrower then determines whether to honor his/her repayment promise to the investor. Our experimental design implements this scenario to

\footnotetext{
${ }^{3}$ In contrast to free-form communication, "bare-form" pre-play communication, often called the "bare-promise" protocol in the literature, is an experimental treatment designed to permit a promise to be communicated without embellishment. This creates a more focused and demanding test of the role played by promises per se in the absence of the individual rhetorical flourishes that occur with free-form communication.
} 
study the effects of relational closeness (guanxi) and identifiability (working through mianzi or face concerns) on contingent promises in China.

Guanxi is an indigenous concept familiar to virtually every Chinese person (Chiao, 1982; King, 1991). It expresses the central importance of relationships within Chinese society (e.g., Song et al., 2012; Yang, 1994). Management researchers have explored different ways to operationalize the concept of guanxi and examine its impact on various interpersonal interactions in China (e.g., Chen et al., 2013; Chai \& Rhee, 2010; Farh et al., 1998; Luo, 2000; Tsui \& Farh, 1997; Xin \& Pearce, 1996; Yang, 1994). Song et al. (2012) recently examined the influence of guanxi on levels of trust and reciprocity in China. They represented the level of guanxi by comparing decisions of classmates with those of demographically identical non-classmates in a standard trust/investment game. The results showed that guanxi had a significant impact on behavioral trust, represented by the amount of money sent by the trustor to the trustee. However, reciprocity, represented by the ratio of the amount of money returned to the amount of money initially sent, was not responsive to their guanxi manipulation. Their study did not permit promises or any other form of communication between the participants in an exchange.

We follow Song et al. (2012) in using the classmate/non-classmate manipulation to represent the level of guanxi or relational closeness in our setting. An alternative approach would try building guanxi in the laboratory using a minimal-group paradigm manipulation (Tajfel \& Turner 1979). However, cross-cultural research suggests that the minimal group paradigm provides a less effective representation of affiliation with a group in less individualistic cultures where groups are slower to form (Mann et al. 1985). China is generally considered such a culture. Thus, rather than implementing an ad hoc group-formation manipulation, we base our relational closeness manipulation on the two naturally occurring relationship categories employed by Song et al. (2012): classmate shouren and non-classmate shengren, holding other demographic variables constant. Our first hypothesis focuses on the role played by relational closeness in affecting the propensity to keep a promise. 
Hypothesis 1: There will be a greater propensity for a borrower to keep a promise to return a specified sum of money to an investor among classmates (representing shouren guanxi) than among non-classmates (representing shengren guanxi).

In addition to examining the effect of relational closeness, we study the effect of identifiability, whether or not a decision can be linked to the specific decision-maker. Mainstream experimental economic and psychology research often imposes anonymity among laboratory participants. In contrast, outside the laboratory doors most socio-economic exchanges are conducted between people who have some knowledge of the identity of the interacting party. Thus, it is empirically important to examine the role played by identifiability versus anonymity. Identifiability can influence the propensity to keep contingent promises through the following two mechanisms. First, identifiability puts an economic exchange into a social environment, which may bring norms defined by society into an economic exchange (Roth, 1995). This may be particularly salient in China, a culture for which social image concerns (mianzi) is a particularly important social norm. Second, identifiability creates the potential for future social sanctions, which may effectively curtail socially undesirable behavior as earlier work that examined the effect of "double-blind" procedures has suggested (e.g. Hoffman et al., 1994). This mechanism may be especially salient among classmates, who are more likely to interact on a continuing basis after the experiment is over. Thus, it leads to the prediction that the level of identifiability might be a more important determinant of promise-keeping among classmates than among strangers. Earlier studies have provided evidence that identifiability induces individuals to converge to social norms such as cooperation in the Prisoner's Dilemma Game and fairness in the Dictator Game (e.g., Bohnet \& Frey, 1999). However, to our knowledge nobody has examined experimentally the effect of identifiability on the keeping of promises.

We argue that maintaining or gaining face or mianzi requires such identifiability in China. Mianzi, like guanxi, is an essential element in Chinese culture. It denotes one's social status and prestige in one's social circle (e.g, Fei, 2012; Hu, 1944). People obtain mianzi through being 
perceived by others as successfully performing a positive social role or conforming to societal norms and values. Thus, maintaining or gaining mianzi, via actions that create a favorable impression in others' minds (Schlenker 1980; Schneider 1969, 1981; Tedeschi \& Riess 1981) can be an important motivation in Chinese society. Indeed, Kachelmeier and Shehata (1997) demonstrate that identifiability significantly increases contributions in a voluntary contribution game in China, but not in Canada. Our study will examine whether the Chinese cultural emphasis on building and maintaining mianzi (face), which requires identifiability, makes such identifiability a particularly salient determinant of the propensity to keep promises in the Chinese context. Identical treatments in New Zealand act as a cultural control, since social image concerns are hypothesized to be less salient in a non-Asian culture. Hence the second two-part hypothesis proposes an impact of identifiability on the propensity to keep a promise, incorporating the idea that this effect may be particularly strong among classmates who will have continuing interactions with each other. The third hypothesis proposes a cultural impact on the strength of this identifiability effect.

Hypothesis 2: (a) There will be a greater propensity for a borrower to keep a promise to return a specified sum of money to an investor when they both know that each party will be informed of each other's identity after the borrower's decision has been made. (b) This effect will be particularly pronounced among classmates.

Hypothesis 3: There is no effect of mutual identifiability on the propensity of a borrower to keep a promise to return a specified sum of money to an investor in New Zealand.

When borrowers are more likely to keep their promises, investors will be more likely to trust them and thus accept their proposals. Since borrowers and investors are selected from the same population and randomly assigned to their roles in the experiment before the first period begins, it seems plausible that investors will have some understanding of how borrowers will react to the experimental environment in which they find themselves. Moreover, the experiment takes place over ten periods. Subjects remain in the same role throughout the experimental 
session. A borrower (investor) is matched with a different investor (borrower) in in each of the ten periods in a session so that the same borrower-investor pair are matched together only once during the experiment. After each period, each investor who has accepted a proposal to lend money to a borrower finds out how much the borrower has sent back, and thus learns whether the borrower kept the promise made in his/her proposal or not. Thus, we hypothesize that factors that favor the keeping of promises will also favor the acceptance of proposals, as investors learn from experience whether they can trust the borrowers with whom they are paired to keep their promises. Since experience accrues over time, this effect will emerge over time, becoming most evident towards the end of the ten periods of the experiment.

Hypothesis 4: There will be a greater propensity for an investor to accept a borrower's proposal among classmates than among non-classmates. This effect will emerge slowly with experience over time, and manifest itself toward the end of the ten-period experiment.

Hypothesis 5: There will be a greater propensity for an investor to accept a borrower's proposal when they both know that each party will be informed of each other's identity at the end of the period after all decisions have been made. This effect will emerge slowly with experience over time, and manifest itself toward the end of the ten-period experiment.

\section{Experimental Design}

\subsection{Overview}

In the laboratory we use a new variant of the trust/investment game (Berg et al., 1995) as our vehicle of investigation. In it, both the "borrower" (second mover) and the "investor" (first mover $)^{4}$ will be given the same amount of endowment $\mathrm{E}$ at the beginning of the game. The borrower is then given the opportunity to request that the investor send him/her an amount of money chosen by the borrower. In exchange, the borrower makes a promise contingent on receiving the requested funds to the investor before the investor decides whether or not to send those funds to the borrower. The specific game is played as follows:

\footnotetext{
${ }^{4}$ In the experiment itself, we do not use such contextual labels. Instead, subjects are randomly designated as "Player A" or "Player B".
} 
Stage 1: The borrower proposes a contract that includes a binding amount $\mathrm{X}$ to be sent by the investor and a non-binding promise $\mathrm{Y}^{*} . \mathrm{X}$ is an integer between 0 and the endowment $\mathrm{E}$ (including 0 and $\mathrm{E}$ ), and $\mathrm{Y}^{*}$ is an integer between 0 and $3 \mathrm{X}$ (including 0 and $3 \mathrm{X}$ ).

Stage 2: After reading the proposal, the investor decides whether to accept the proposal. If she accepts, the game enters the next stage. If she rejects, the game ends.

Stage 3: The borrower sends the actual amount $\mathrm{Y}$ back to the investor, where $\mathrm{Y}$ is an integer between 0 and $3 \mathrm{X}$ inclusive. $\mathrm{Y}$ may either be the same, higher, or lower than the proposed $\mathrm{Y}^{*}$.

If the investor rejects the proposal, both the investor and the borrower keep the initial endowment E. If the investor accepts the proposal, then the investor sends $\mathrm{X}$ to the borrower. The amount sent $(\mathrm{X})$ is tripled by the experimenter before the borrower receives it, thus creating surplus. This surplus can be thought of as a simple representation of either the net present value of a project undertaken by a borrower and/or a borrower's consumer surplus if the loan is used for consumption purposes. After the borrower sends $\mathrm{Y}$ back to the investor, the investor earns $\mathrm{E}-$ $\mathrm{X}+\mathrm{Y}$, and the borrower earns $\mathrm{E}+3 \mathrm{X}-\mathrm{Y}$.

Finally, we adopt the strategy method (Selten, 1967) to observe the borrower's actual reciprocity decision. Specifically, before the investor's decision, whether to take up the borrower's proposal or exit the game, is revealed to the borrower, the borrower must commit to a response decision to be implemented if the proposal is accepted by the investor. ${ }^{5}$ This decision may or may not be consistent with the contingent promise made by the borrower.

The Pareto optimal outcome in such a game is as follows: the borrower proposes $\mathrm{X}=\mathrm{E}$ and $\mathrm{E} \leq \mathrm{Y}^{*} \leq 3 \mathrm{E}$; the investor accepts and the borrower keeps the promise by choosing $\mathrm{Y}=\mathrm{Y}^{*}$. In contrast, non-cooperative game theory predicts that borrowers, if self-interested, rational, and motivated to maximize their wealth, would send no money back to investors regardless of the

\footnotetext{
${ }^{5}$ Asking each borrower to make a reciprocity decision prior to receiving the investor's decision to transact or not is an example of the "strategy method" of gathering decision data (e.g., Selten, 1967). It allows data to be gathered both at observed and unobserved decision nodes of the game. A possible disadvantage is that the psychological saliency of the reciprocity decision could be moderated by such a procedure. Cason and Mui (1998) and Brandts and Charness (2000) examined this issue empirically. Both studies found that in games of low complexity there is no difference in behavior when such a manipulation was adopted.
} 
promise they made in the first stage. Since there is no way of penalizing such self-interested behavior, rational investors should then correctly expect borrowers to send nothing back. Therefore, self-interested investors have no motivation to send anything to borrowers. Thus the sub-game perfect Nash equilibrium predicts neither trust nor promise-keeping behavior in such a setting and the opportunity for a mutually beneficial transaction is forgone. However, the borrower's preference for promise-keeping could make a difference. Consider the following extreme case: suppose the borrower is a strong "promise-keeper", which means that the borrower never deviates from a promised action. If the investor knows the borrower's attitude toward promise keeping, the Pareto optimal outcome will prevail.

We employ a two-by-two factorial design to study the impact of the two factors discussed above on promise-keeping behavior. Those two factors are relational closeness (guanxi) and whether or not parties to an exchange are identifiable to each other (mianzi). Relational closeness is represented by whether or not the two participants in the exchange pair are classmates or strangers. The level of identifiability is manipulated by either revealing or hiding the identities of both parties to each other at the end of an interaction. In the baseline Stranger-NoID treatment, subjects interacted with non-classmate strangers and subjects could not observe the identity of the person with whom they were interacting. The Classmate-NoID treatment had the same lack of identifiability, but everyone in the session was recruited from the same class. All subjects were demographically similar other than whether or not they were classmates. The third and fourth Stranger-ID and Classmate-ID treatments manipulated the identifiability factor. Specifically, each subject's ID was prominently displayed on a large card sitting on top of the computer terminal at which the subject was sitting so that all other subjects in the session could easily identify other decision-makers by ID. After each decision period ended, the ID number of the matched counterpart was revealed to a subject on his/her computer screen as summary information about that period.

\subsection{Experimental Procedure}


We conducted all four treatments at Zhejiang University in China. As noted above, it was impossible to run the identical classmate/non-classmate treatment in New Zealand because students are not organized into classes in New Zealand as they are in China. However, we did conduct the two stranger treatments (manipulating identifiability) at the University of Canterbury in New Zealand to explore whether and to what extent culture moderates the identifiability effect on promise keeping. ${ }^{6}$ We paid special attention to the physical set-up of the labs in each country to ensure that participants were equally visible to other participants in both countries. Privacy partitions were not used in either lab. This was important to ensure that the identifiability treatments in both countries were comparable. Moreover, the same co-author conducted the experiments in both labs. All sessions were programmed using Visual Basic 6.0. Both the instructions and the information shown on the computer screen were in Chinese for the sessions conducted in China and in English for those conducted in New Zealand. Subjects in both countries were recruited from a campus-wide list of undergraduate students who had previously responded to advertisements in classes or on the web. They were informed at the time of recruitment that they would receive money for their participation and the exact amount would depend on their decisions and those of others in the experiment. No participants had any experience with investment/trust-game experiments and no one was permitted to be in more than one session.

In each session there were 20 participants, who played the game for 10 periods. Before the first period began, subjects were randomly assigned to be either Player A (the investor) or Player B (the borrower). Subjects remained in the same role throughout the experimental session. A Player A was matched with a different Player B in each of the ten periods in a session so that the same Player A and Player B pair were matched together only once during the experiment. A decision in a given period was transmitted only to the counterpart in that period. No other

\footnotetext{
${ }^{6}$ We thank Maros Servatka for his generous hospitality and assistance in running these sessions.
} 
subjects were informed of the decision. To avoid wealth effects, only one of the ten periods was randomly chosen for payment at the end of the session.

We ran 16 sessions (320 subjects, 145 were male, average age was 20.79) in China with 80 subjects in each of the four treatments and another 8 sessions (160 subjects, 79 were male, average age was 22.01 in total) in New Zealand sessions with 80 subjects in each of the two treatments. The initial endowment E was set at 20 RMB in China and 10 NZD in New Zealand for both Player A and Player B. Each session generally lasted less than one hour (including the time for reading instructions). The average payment was $41.75 \mathrm{RMB}$, including a $10 \mathrm{RMB}$ showup fee for the Chinese subjects (the exchange rate was $\$ 1 \mathrm{US}=6.50 \mathrm{RMB}$ ). Since the average hourly wage in China for a college graduate is about 15 to $20 \mathrm{RMB}$, the payment was a meaningful amount for the undergraduate subjects. The average payment was $\$ 34.19$ in New Zealand dollars, including a \$5 show-up fee for the New Zealand subjects. Given the adult minimum wage in New Zealand at the time of the experiment was 12 NZD per hour, the average payment in New Zealand was salient and equivalent in purchasing power to the payouts in China.

\section{Results}

\subsection{Data Summary}

Table 1 and Figures 1 to 3 report summary data for all treatments. While Table 1 reports means and standard errors over all ten periods combined, the figures show the evolution of the data over time. To make data in New Zealand comparable to data in China, we scaled up New Zealand data by $2{ }^{7}$ We focus on the following key variables: 1) Proposed Amount to Send - the amount the borrower requests from the investor in his/her proposal; 2) Proposed Amount to Return - the amount that the borrower promises to return to the investor contingent on the investor accepting his/her proposal; 3) Proposed Reciprocity Ratio - the proposed amount to return divided by the proposed amount to send; 4) Proportion of Promises Kept - the proportion

\footnotetext{
${ }^{7}$ Recall that the initial endowment was 20 RMB in China and 10 NZD in New Zealand.
} 
of times for which the actual amount returned was greater than or equal to the amount promised; ${ }^{8}$ 5) Proportion of Proposals Accepted - the proportion of borrower proposals that were accepted by investors; 6) Actual Amount Sent - the actual amount sent is equal to the proposed amount for accepted proposals and equal to zero otherwise; 7) Actual Amount Returned for Accepted Promises - the amount actually sent by borrowers back to investors who had accepted their proposals; 8) - Actual Reciprocity Ratio for Accepted Proposals - the actual amount returned divided by the actual amount sent for accepted proposals.

A glance at Table 1 reveals that both relational closeness and identifiability seem to induce a higher propensity to keep promises, especially in China. Figure 1 suggests that the six treatments may be divided into two subgroups. Specifically, the promise-keeping propensity appears to be lower for the China-Stranger-NoID control treatment and the two New Zealand treatments than for the three other Chinese treatments involving the relational closeness manipulation, the identifiability manipulation, or both. In Table 1, both factors also appear to be associated with a higher proportion of accepted proposals, though this association appears weaker than the association with promise-keeping. Figure 2 suggests that while there is no clear distinction early on between the treatments regarding the acceptance of proposals, a separation echoing the one in Figure 1 does seem to emerge as the game evolves. Investors seem to be reacting to lower levels of promise-keeping by accepting fewer promises over time. This is particularly clear for the New Zealand treatments, only becoming apparent in the China-StangerNoID control treatment during the last two periods of the game. The actual amount sent also appears to be higher in the treatments involving relational closeness and/or identifiability. Figure 3 shows a similar but slightly more pronounced separation for actual amount sent emerging over time between the same two treatment subgroups. Of course, this is just an impressionistic description of the data. To rigorously test our hypotheses, we estimate several dummy-variable regression models below.

\footnotetext{
${ }^{8}$ Out of 1280 promises that were kept, the actual amount returned was greater than the amount promised 50 times and equal to the amount promised 1230 times.
} 


\subsection{Regression Analysis}

The figures indicate that several treatment effects appear to emerge after repeated play with different partners over time. Thus, it is imperative to incorporate time into our analysis, and this necessitates taking account of the panel nature of our data. We do so by utilizing appropriate random-effects regression models. All of the regressions use a dummy-variable coding selected to highlight the hypothesized treatment effects. The name of each dummy variable represents the treatment or treatments for which the dummy is set equal to 1. For example, the dummy variable called NZ is set to 1 for both New Zealand treatments, while the variable NZ_ID is set to 1 only for the New Zealand-ID treatment. The coding is fully outlined and explained in Table 2 . The passage of time is represented by the variable Period, a simple linear time trend centered at the final period 10. In some cases, we interact Period with the various treatment variables and test to see whether the dependent variable is evolving in a significantly different manner under different treatments over time. The centering of Period implies that in such cases all treatment effects are estimated for the final period of the experiment. ${ }^{9}$

Hypotheses 1, 2, and 3 all concern the propensity of borrowers to keep a contingent promise. To examine these hypotheses, we run four logistic regressions reported in Table $3 .{ }^{10}$ In each case, the dependent variable is whether or not a contingent promise was kept for each of the 240 subjects in each of the ten periods for a total of 2400 observations. Since all borrowers make a binding decision about how much they would actually return prior to finding out whether the proposal containing their contingent repayment promise was accepted, we have an observation on whether the promise would have been kept for each borrower in every period. We employ a random effect for each borrower because borrowers may have idiosyncratic attitudes toward

\footnotetext{
${ }^{9}$ Cohen et al. (261-282, especially p. 281) contains an excellent discussion about centering and the proper interpretation of centered versus non-centered variables.

${ }^{10}$ Two alternative approaches to estimating a model for a binary dependent variable are to use the probit or linearprobability specifications. In addition to logistic models, we tried both of these specifications for all models in this paper involving a binary dependent variable. There were no important qualitative differences in the results.
} 
promise keeping that persist over time. To be conservative, all reported significance levels and $p$ values are for two-tailed tests.

Model 1 uses all of the treatment dummies specified in Table 2, interacting each with Period. Although promise keeping is falling over time regardless of treatment, none of these interactions is significant. A test of the null hypothesis that all of the interactions are jointly equal to zero cannot be rejected $(p=0.66)$. Therefore we drop the interactions and focus on Model 2.

In Model 2, the significance of China_Class at the 5\% level $(p=0.01)$ means that when participants were not identifiable, borrowers were more likely to send back the amount of money promised if they were matched with another classmate than if they were matched with a stranger. This supports the relational closeness effect specified in Hypothesis 1. A supplementary test reveals however that when participants were identifiable, the likelihood of a borrower honoring his/her promise was not significantly different when matched with a classmate than when matched with a stranger $(p=0.52) .{ }^{11}$ Thus, while Hypothesis 1 is corroborated under anonymity, it is not supported when participants are mutually identifiable.

We observe a similar result for Hypothesis 2. China_Stranger_ID is significant at the $1 \%$ level $(p=0.009)$, indicating that when strangers are mutually identifiable, a borrower is more likely to keep his/her promise to send back a specified sum of money to the investor than when strangers are not identifiable. This supports a role for identifiability as specified in Hypothesis $2 \mathrm{a}$. However, China_Class_ID is not significant. This implies that mutual identifiability makes no difference for classmates. This result was directly contrary to Hypothesis $2 b$, which predicted a stronger identifiability effect for classmates than for strangers.

Hypothesis $2 \mathrm{~b}$ reflected our expectations that relational closeness and mutual identifiability would be complements, but they turned out instead to be substitutes. A subgroup of people who might be inclined to promise more than they would actually deliver to an anonymous stranger were more likely to keep their promise to an anonymous classmate. Similarly, a

\footnotetext{
${ }^{11}$ The null hypothesis tested is China_Class + China_Class_ID - China_Stranger_ID = 0 .
} 
subgroup willing to break a promise to an anonymous stranger were more likely to keep their promise when they knew that their identity would be revealed to the stranger and the stranger's identity would be revealed to them. Both of these manipulations brought the rate of promise keeping up to similar level: $62 \%$ in the Classmate-NoID treatment and $66 \%$ in the Stranger-ID treatment compared to $44 \%$ in the baseline Stranger-NoID treatment. In the Classmate-ID treatment, the rate was higher at $70 \%$, but not significantly so. We conjecture that there is a group of people who are willing to make and then break a promise in order to obtain money from another person regardless of the level of relational closeness or identifiability. Manipulating one of these factors appears to be sufficient to coax out more honesty in those subjects who approach the honoring of such a promise differently in different situations. Manipulating the other factor has little or no further impact on the behavior of those determined to break a promise in order to increase their profits.

Returning to Model 2 to investigate Hypothesis 3, we find that NZ_ID is not significant, indicating the lack of an identifiability effect for strangers in New Zealand. This stands in contrast to the significance of this effect in China, corroborating Hypothesis 3. It is interesting to note that NZ is not significant, implying that there is no significant difference between New Zealand and China in the propensity to keep a contingent promise among anonymous strangers. On the other hand, because maintaining face may matter more in China than in New Zealand, the rate of promise keeping is significantly higher in China than in New Zealand among mutually identifiable strangers $(p=0.01) .^{12}$

Models 3 and 4 add two covariates to the analysis: the Proposed Amount to Send and the Proposed Reciprocity Ratio. The idea is that a borrower is more likely to keep his/her promise when it does not seem too onerous to do so. The more that is sent, all other things being equal, the less onerous it may feel to send back the promised sum. Similarly, the greater the promised sum relative to the amount sent, namely the Proposed Reciprocity Ratio, the more onerous it may

\footnotetext{
${ }^{12}$ The null hypothesis tested is China_Stranger_ID $-\left(\mathrm{NZ}+\mathrm{NZ} \_\mathrm{ID}\right)=0$.
} 
feel to send back the promised amount. In both models, these covariates are significant at the $1 \%$ level in the expected direction. However, controlling for these covariates makes virtually no difference to the results already discussed. The only difference is that in Model 4, China_Class is now significant at the $1 \%$ rather than the $5 \%$ level $(p=0.007)$. Thus, our conclusions are robust to the presence of these covariates. ${ }^{13}$

Hypotheses 4 and 5 both concern the propensity of investors to accept proposals. To examine them, we estimate two logistic models. Since each potential investor makes ten repeated decisions paired with different borrowers, we employ a random effect for each investor to deal with the possibility of idiosyncratic investor effects. In Model 1, we use Period and the dummyvariable coding presented in Table 2, interacting each dummy variable with Period. A joint test rejects the null hypothesis that all of the interactions are equal to zero $(p=0.02)$. Thus, we retain the interactions and focus on Model 1.

Hypothesis 4 is supported by the coefficient on China_Class, which is significant at the $5 \%$ level $(p=0.01)$, implying that there is a higher rate of proposal acceptance among nonidentifiable classmates than among non-identifiable strangers by the final period of the experiment. ${ }^{14}$ This effect emerges gradually over the course of the experiment as predicted by Hypothesis 4. To see why this happens, notice that the coefficient on Period is equal to -0.11 and significant at the $1 \%$ level $(p=0.009)$. This implies that the acceptance of proposals is falling over time for the China-Stranger-NoID control treatment. This is an understandable reaction to the relatively low (44\%) rate of promise keeping in that treatment. In contrast, the interaction between China_Class and Period is equal to 0.12 and significant, albeit marginally at the $10 \%$ level $(p=0.07)$. Since 0.12 more than offsets -0.11 , the rate at which proposals are being

\footnotetext{
${ }^{13}$ It is important to note that it is not correct to give a causal interpretation to the relationship between either of these covariates and the probability of keeping a contingent promise. This is because the borrower makes all three of these decisions simultaneously. S/he may for example promise to send a lot back (i.e. a high Proposed Reciprocity Ratio) because s/he does not intend to keep his or her promise, or s/he may decide not to keep his or her promise because s/he has promised to send so much back relative to the amount sent. The causation is therefore not clear. The significance of the covariates demonstrates only correlation.

${ }^{14}$ Recall that Period is centered at the final period. Thus, treatment effects in regressions containing interactions with Period are estimated for the final period.
} 
accepted is relatively stable over time for classmates. We conjecture that this reflects the higher rate at which promises are kept $(62 \%)$ in the China-Classmate-NoID treatment. Thus, a gap opens up between the acceptance of proposals in the China-Classmate-NoId treatment and the ChinaStranger-NoID control treatment, resulting in the observed treatment effect toward the end of the experiment represented by the significant coefficient on China_Class.

Recall that for when examining the evidence for Hypothesis 1 we found a significant relational closeness effect under the anonymous NoID protocol, but not under the protocol where participants were mutually identifiable to the person with whom they were interacting. Not surprisingly, this effect is echoed for Hypothesis 4. Since the promise-keeping rate was not significantly higher for identifiable classmates than for identifiable strangers, the rate at which proposals were accepted did not diverge significantly either $(p=0.29){ }^{15}$

For Hypothesis 5, the story is similar, though the statistical evidence is somewhat weaker. China_Stranger_ID is significant, albeit marginally $(p=0.06)$. This suggests that mutual identifiability is associated with the emergence of a higher rate of proposal acceptance for strangers by the final period. As in the case of Hypothesis 2, there is no such effect for classmates as evidenced by the insignificance of China_Class_ID.

Also consistent with the evidence for Hypothesis 3, which indicated no identifiability effect on promise-keeping for New Zealand, is the similar lack of any such effect on the acceptance of proposals among the New Zealand participants as evidenced by the insignificance of NZ_ID. However, despite the fact that under the anonymous protocol New Zealanders did not break their promises significantly more than Chinese, they were significantly less prone to accept proposals as evidenced by the negative coefficient on NZ, which is significant at the $5 \%$ level $(p$ $=0.02)$.

Model 1 examines treatment effects over time in the absence of any other explanatory variables. However, investors are likely to attend not only to the treatment variables, but also to

\footnotetext{
15 The null hypothesis tested is China_Class + China_Class_ID - China_Stranger_ID $=0$.
} 
the various other pieces of information at their disposal when deciding whether or not to accept a proposal. The first of these is the amount the borrower is asking for, the Proposed Amount to Send $(\mathrm{X})$. A higher $\mathrm{X}$ means that more is at stake and that an investor is risking the loss of a higher amount of money by accepting the proposal. All other things being equal, a higher X should therefore make an investor less likely to accept a proposal. ${ }^{16}$

The second piece of information at the disposal of investors is the Proposed Reciprocity Ratio, i.e. how much the borrower is promising to send back relative to the amount sent if the investor accepts the proposal (Y/X). A higher $\mathrm{Y} / \mathrm{X}$ means that if the promise is honored, the investor receives a higher rate of return on his/her investment. All other things being equal, this should make a proposal more tempting and thus be associated with a higher acceptance rate. ${ }^{17}$ The third piece of information is the experience of the investor in previous periods. In particular, each investor who has accepted one or more proposals in previous periods knows the proportion of resulting contingent promises that were kept. Since one's past experience in a previously unfamiliar environment is often the best way to predict future experience, an investor who has encountered a higher rate of promise keeping in previous periods is more likely to be optimistic enough to accept a current proposal than an investor who has experienced a lower promise-keeping rate. The previously observed promise-keeping rate is specified as the number of promises that have been kept divided by the number of proposals that have been accepted prior to the current period. Since nobody has had any experience in period one, this variable is not defined for that period. Similarly, if in any given period a participant has not yet accepted any

\footnotetext{
${ }^{16}$ On the other hand, all other things may not be equal. In particular, we showed earlier (see Model 4 in Table 3) that a higher $\mathrm{X}$ is associated with a significantly greater chance of a borrower keeping his/her promise. If investors realize this, it might work in the opposite direction, making investors more rather than less inclined to accept a proposal with a higher X. Thus, precisely whether and how X might affect the decisions of investors is ultimately an empirical matter.

${ }^{17}$ As in footnote 17 above, other things may not be equal. In particular, we showed earlier (see Model 4 in Table 3) that a higher $\mathrm{Y} / \mathrm{X}$ is associated with a significantly lower chance of a borrower keeping his/her promise. If investors realize this, they might be less likely to accept a proposal with a higher $\mathrm{Y} / \mathrm{X}$ since that more tempting promise is less likely to be kept. Thus, as with the Proposed Amount to Send, it is difficult to predict a priori whether and how the level of Y/X will affect the decisions of investors.
} 
proposals, s/he will have no relevant experience. Therefore, in Model 2 we drop all data from the first period and for any other decision prior to which there has been no experience of a promise.

Each of these pieces of information is significant at the $1 \%$ level as reported in Table 4, Model 2. A higher X reduces the likelihood of a proposal being accepted, while a higher Y/X increases the likelihood. As predicted a better experience with promises being kept in previous periods also raises the likelihood that a potential investor will accept a proposal. When these three covariates are added to the regression, both the relational closeness and identifiability effects vanish in the Chinese data. In contrast, the proposal-acceptance rate in the New Zealand Stranger-NoID treatment continues to be significantly lower than in the comparable Chinese treatment $(p=0.02)$. Moreover, a marginally significant identifiability effect arises in the New Zealand data $(p=0.09)$. Why does this occur?

To answer this question, we estimate random-effect (for each borrower) regression models of the Proposed Amount to Send (X) and the Proposed Reciprocity Ratio (Y/X) in Table 5. For the former, there are significant interactions of the treatment variables with Period. Therefore the interactions are retained. For the latter, this is not the case. Therefore, we drop the interactions and focus on Model 2. Notice that neither X nor $\mathrm{Y} / \mathrm{X}$ is significantly different in New Zealand from the China-Stranger-NoID control treatment. In contrast, $\mathrm{X}$ is significantly higher at the 5\% level in the China-Classmate-NoID treatment $(p=0.03)$ and significantly higher at the marginal 10\% level in the China-Stranger-ID treatment $(p=0.08)$ than in the control. Moreover, $\mathrm{Y} / \mathrm{X}$ is also significantly higher at the 5\% level in the China-Classmate-NoID treatment than in the control $(p=0.02)$. This implies that there are relational-closeness effects on both $\mathrm{X}$ and $\mathrm{Y} / \mathrm{X}$. Essentially more is demanded from classmates, while simultaneously more is promised in return. Making strangers mutually identifiable produces a weaker but still marginally significant effect on the amount borrowers are prepared to request. Thus, both of these covariates are themselves related to the Chinese treatment variables, but do not differ between either of the New Zealand treatments and the Chinese control. 
What about experience? Every proposal made by a borrower contains a contingent promise. If an investor accepts a proposal, that investor subsequently learns whether or not the promise associated with the proposal was kept or broken. In Table 6, we report the results of a Negative Binomial Regression that examines the number of promises kept for each investor, appropriately adjusted for the number of accepted proposals. The adjustment is equivalent to transforming the dependent variable, which is the number of promises kept, into the proportion of promises associated with accepted proposals that were kept for each investor. Thus, there are 237 observations, one for each participant who accepted at least one proposal. ${ }^{18}$ In the Chinese data, there are clear relational-closeness effects under anonymity and identifiability effects for strangers at the $5 \%(p=0.04)$ and $1 \%(p=0.01)$ levels respectively. ${ }^{19}$ There are no significant effects for New Zealand or differentiating the New Zealand data from the Chinese-StrangerNoID control treatment.

The fact that all three of the covariates used in Model 2 are significantly related to relational closeness while two are related to mutual identifiability in China suggests that they are acting as mediators (Baron \& Kenny, 1986) for the effect of relational closeness and identifiability on the acceptance of proposals by investors. In fact, they completely mediate the treatment effects for China. In contrast, the fact that none of these covariates is significantly related to any treatment effect involving New Zealand means that they are unrelated to the treatment effect for New Zealand that is carried over from Model 1 to Model 2. The marginal identifiability effect that appears to emerge for the New Zealand participants occurs because with the addition of the covariates an insignificant $p$-value of 0.12 for NZ_ID in Model 1 falls to 0.09 in Model 2, slightly below the $10 \%$ marginal significance level.

\footnotetext{
${ }^{18}$ Three participants did not accept any proposals and thus had no experience with promises.

${ }^{19}$ The incidence rate ratios (IRR's) are simply ratios of the incidence of promise keeping under the different treatments. For example, for China_Class, there is an IRR of 1.51. This means that the fitted rate of promise keeping for accepted proposals is 51\% higher under the China-Classmate-NoID treatment than under the China-StrangerNoID control treatment.
} 
The upshot of this analysis is that there are significant treatment effects on the rate of proposal acceptance both for Chinese subjects and between subjects in China and those in New Zealand. However, they differ in an important way. Consider two Chinese investors who have previously experienced an identical proportion of promises made to them being kept. Suppose that each faces a request from a borrower for the same amount of money $\mathrm{X}^{*}$ with a contingent promise to repay an identical amount $\mathrm{Y}^{*}$. The predicted probabilities of the two investors accepting the proposal are also identical regardless of whether they are classmates or strangers, anonymous or mutually identifiable. All of the treatment effects on proposal acceptance in China work through their effects on $\mathrm{X}, \mathrm{Y} / \mathrm{X}$ and the differing experiences of promise keeping under the different levels of relational closeness and identifiability. In contrast, comparing a New Zealand investor with a Chinese investor in the correspondingly identical situation, the investor in New Zealand would be significantly less likely to accept the proposal than the investor in China.

The differing rates of promise keeping and proposal acceptance influence the Actual Amount Sent, and hence the amount of surplus created by the peer-to-peer lending transaction. In Table 7, we present the results of a regression of the Actual Amount Sent on Period and the treatment dummies. The Actual Amount Sent is directly affected both by the Proposed Amount X determined by the borrower and whether or not the investor decides to accept the borrower's proposal. Therefore, we employ cross-random effects for each borrower and investor. Since there are significant interactions between Period and the treatment variables, we retain the interactions. Reflecting the earlier results for the Proposed Amount to Send and the Proportion of Proposals Accepted, we find positive and significant effects at the $1 \%$ level for China_Class $(p=0.001)$ and China_Stranger_ID $(p=0.005)$. This implies that relational closeness and identifiability each promote the trust necessary to create surplus, and act as substitutes for each other. This is because the presence of either creates an environment in which investors soon learn that promises are kept more often. For New Zealand, the Actual Amount Sent is significantly lower at the 5\% level for the Stranger-NoID treatment than for the comparable treatment in China $(p=0.02)$. This is 
consistent with significantly fewer proposals being accepted in New Zealand. Moreover, identifiability has a positive effect on the amount sent, significant at the $5 \%$ level $(p=0.02)$. In contrast to China, these results are not rooted in significantly different experiences with the credibility of promises either between anonymous strangers in China and New Zealand or between anonymous and identifiable strangers in New Zealand itself.

\section{Discussion and Conclusion}

\subsection{Key Findings, Implications for Theory and Practice}

In this paper, we conducted a laboratory experiment that captures key features of internet peer-to-peer (P2P) micro-financing to examine the role played by relational closeness (guanxi) and mutual identifiability (mianzi) on the keeping and accepting of promises in a one-shot sequential exchange between a potential investor and a potential borrower. In our set-up, the borrower makes a contingent promise to the investor by means of a pre-play proposal, which the investor can choose either to accept or reject. Acceptance of the proposal involves sending the borrower the requested sum; rejection of the proposal involves keeping one's endowment and not participating in the proposed transaction. The borrower can then either keep his/her promise or defect by sending less than the promised amount. We manipulated the relational closeness between the two parties by comparing classmates with demographically identical non-classmates (strangers), categories often associated with different levels of relational closeness in the context of Chinese culture. To examine the impact of identifiability, we compared completely anonymous transactions with those for which the parties knew they would be mutually identifiable after their decisions were made. These two factors were crossed, leading to a two-bytwo factorial design in China. In addition to these four treatments. we conducted the identifiability manipulation in New Zealand to add a cultural control. The lack of close-knit classes in New Zealand made it impossible to conduct the classmate-stranger manipulation there.

Our experiment yields several key findings. First, in China classmates exhibited a 
significantly higher propensity to keep promises than strangers when the parties were anonymous, suggesting relational closeness can significantly affect one's propensity to keep a promise. Second, among non-classmate strangers in China the mutual identifiability of the transacting parties produced a significantly higher tendency to keep promises, indicating the critical role played by identifiability in promoting promise-keeping. Third, a closer relationship level did not translate into a significant increase in promise-keeping among mutually identifiable participants, nor did mutual identifiability produce a significant increase among classmates. This suggests that relational closeness and identifiability are substitutes: the presence of at least one of them promotes promise-keeping, but the presence of both produces no significant additional benefit.

Fourth, over time the higher rates of promise-keeping linked with the presence of relational closeness or identifiability built trust among investors in China, so that they accepted more proposals, resulting in more investment and the creation of greater social surplus. More specifically, an investor's experience with the credibility of promises in previous periods along with the treatment-related amount the borrower requested (Proposed Amount to Send) and the treatment-related promised return on investment (Proposed Reciprocity Ratio) completely mediated the relational-closeness and identifiability effects on the acceptance of proposals for China.

Fifth, there were no significant differences in the propensity to keep promises between anonymous strangers in New Zealand and anonymous strangers in China. Moreover, in New Zealand mutual identifiability had no impact on the likelihood of a promise being kept. Sixth, anonymous strangers in New Zealand were nonetheless less likely to accept proposals than their Chinese counterparts, resulting in the creation of less investment and hence less social surplus. This unexpected result was not mediated by the experiential covariates that completely mediated the treatment effects in China. It suggests that the New Zealand participants were more cautious or risk-averse about accepting the promises of demographically similar strangers than their 
Chinese counterparts. Also surprising was the marginally significant positive effect of mutual identifiability on the acceptance of proposals in New Zealand, controlling for the experiential covariates. This translated into significantly greater investment and creation of social surplus under the identifiability compared to the anonymous treatment in New Zealand. Identifiability apparently builds trust in New Zealand despite its lack of association with an increase in promisekeeping behavior. This contrasts sharply with China where identifiability appears to build trust precisely because of the associated increase in promise-keeping behavior. This result warrants further investigation.

Our paper extends the literature in several important directions. First, we make an important contribution to the literature on guanxi. To our knowledge, there hasn't been any work that either theoretically or empirically explores whether and to what extent relational closeness (guanxi) may have an impact on promise keeping, an important ethical and social norm crucial for the success of many socio-economic and business endeavors. We hypothesize and demonstrate empirically that a higher level of relational closeness can promote promise-keeping, which is ultimately beneficial to both sides in business dealings as well as to society at large. A recent paper by Song et al. (2012) found that in the context of a standard Trust Game with no promises, the higher level of relational closeness of classmates versus demographically identical nonclasmates significantly increased the level of trust. However, the reciprocity ratio was not affected by it. We show that when the trustee/borrower can make a contingent promise, a higher level of relational closeness significantly increases not only the level of trust, but the level of reciprocity as well. The fact that a certain level of reciprocity has been promised interacts with the level of relational closeness to make this happen.

Second, we explore the effect of identifiability, potentially important because of mianzi or face concerns, another important concept in Chinese culture. Although there is some literature in psychology and economics that concerns the effect of identifiablity versus anonymity on decisions that have social implications, there is no paper to our knowledge that explicitly links 
identifiability in China with ethical or moral behavior. The results in our paper underscore that identifiability indeed is an important consideration for people in deciding whether to keep their promises or not. More importantly, we show that the identifiability effect significantly affects the keeping of promises in China but not in New Zealand, underscoring the salience of such an indigenous concept in the Chinese context ${ }^{20}$.

Our study has many potential implications for business practices in China. Since relational closeness (guanxi) has a significant and positive impact on promised repayments in China, developing microfinance services at Chinese social-network websites (e.g., Chinese Twitter weibo.com, Chinese Facebook renren.com, and applications such as wechat) may be more effective than lending to strangers at a P2P lending site. Similarly, given the saliency of the identifiability (mianzi) effect, providing information about the borrower's and investor's identities, such as photos and personal information, could enhance the likelihood that promised repayments will actually occur. Thus, we strongly recommend business that requires microfinancing to actively build guanxi and seek financing through social-network websites where they already have guanxi ties with potential investors.

A recent article by Ian Johnson in the New York Times (2014) describes how effective such websites can be at raising money for charitable purposes:

When a charity for coal miners was trying to raise $\$ 500$ this year to buy oxygen pumps for a miner dying of black lung disease, its initial appeal fell flat. On a hunch, an employee, Xue Yinhu, appealed to followers on WeChat and raised the money in an hour.

“These people know you better, so they're more willing to support you," he said.

While it has been suggested that guanxi sometimes can contribute to unethical conduct such as nepotism and corruption in Chinese society (e.g., Chen et al., 2004), our findings in this paper, echoing Song et al. (2012), suggest that guanxi can have a positive effect as well by promoting

\footnotetext{
20 Our New Zealand results are congruent with a recent paper by Shutte and Thoma (2014), which also found that identifiability did not affect the propensity for German subjects to keep promises in the context of a one-shot binary trust game.
} 
the keeping of promises, thus enhancing their credibility, and building social norms based on trust and trustworthiness that may eventually extend to more distant guanxi categories, and ultimately to society as a whole.

\subsection{Limitations and Future Directions}

Several features of our empirical investigative strategy deserve attention. First, the logic of laboratory experimentation necessarily requires the elimination or exertion of control over all possible confounding influences other than the critical factors under investigation. The resulting laboratory environment, abstract nature of the experiment, and starkness of the interactions between participants may limit the direct generalizability of the findings to more complex organizational and economic settings. Outside the laboratory, people are likely to be simultaneously influenced by many factors and engage in more complex interactions than a contingent promise and monetary allocation to another party. Thus, although experimental designs maximize the chance of detecting causally valid relationships, they risk reduced external validity.

To mitigate such concerns, our participants were made aware that they were interacting with real counterparts who were also participants like themselves in the experiments. They knew that their decisions would have real and salient monetary consequences. Furthermore, rather than experiencing just one interaction with one counterpart, they experienced ten such interactions within a session, allowing them to learn and adapt as they interacted with ten different counterparts over time.

Second, following Kachelmeier and Shehata (1997), we focused on mutual identifiability versus anonymity as an essential requirement for mianzi. We acknowledge that mianzi and identifiability are not identical. Mianzi is a nuanced, multi-dimensional concept that may influence ethical and moral behavior in a number of ways. Moreover, the presence or absence of mutual identifiablity may have an impact on behavior for reasons other than mianzi. This issue is highlighted by the unexpected effect of identifiability on the Amount Actually Sent in New 
Zealand despite it having no impact on promise keeping. Further research on the nature of mianzi and its relationship to identifiability is clearly needed.

Third, due to the fact that students are not organized into classes in New Zealand as they are in China it was impossible to run the identical classmate/non-classmate treatment in New Zealand as a cultural robustness check for the relational closeness effect on promise keeping. Thus, we were unable to examine whether the effects of relational closeness on promise-keeping are moderated by cultural context. The deep-rootedness of guanxi in China suggests that this could be the case. Future studies should incorporate another manipulation of relational closeness, which is implementable and comparable in both Asian and non-Asian cultures.

Finally, while our game explicitly presented participants with the opportunity to break a promise, other contexts might offer more spontaneous and subtle forms of promise breaking. We believe that a key advantage of confronting participants with an explicit choice between keeping and breaking a promise is that it ensures that their unethical behavior is unambiguous and that the promise-keeping behavior did not result from a lack of perceived options as when it simply does not occur to people that they could break a promise. Nonetheless, future studies might test whether the current findings also apply to more subtle situations with other, naturally occurring forms of communication.

\subsection{Conclusion}

Promise-keeping is one of the most important ethical norms available to engender trust and regulate behavior in business (Gert, 1998). Most human interactions are embedded in social networks and interacting parties are identifiable to varying degrees. Our results suggest that in China the effectiveness of a promise depends critically on the social distance between the interacting parties. A reduction in the social distance, whether based on interacting with an anonymous classmate rather than an anonymous stranger, or based on the knowledge that identities will be revealed once the transaction has taken place, increases the credibility of a promise through increasing the probability of it being kept. Even though both relational closeness 
and mutual identifiability would be regarded as irrelevant by game-theoretic and many neoclassical economic models, our results show that they do affect promise-keeping behavior in China, often regarded as a collective, guanxi- and mianzi-based society. Mutual identifiability did not significantly affect promise-keeping in New Zealand.

Our paper has important implications in facilitating promise-keeping entrepreneurship and in encouraging financing and capital investment in promise-keeping entrepreneurship. Our experimental evidence shows that both relational closeness and identifiability are instrumental for the keeping and accepting of contingent promises concerning monetary transfers in China. Therefore, developing micro-finance services at Chinese social-network websites and smart phone-based application platforms could enhance both the probability that promised repayments will actually occur and the consequent likelihood of investment that creates social benefits.

\section{References}

Baron, R. M., \& Kenny, D. A. (1986). The moderator-mediator variable distinction in social psychological research: Conceptual, strategic and statistical considerations. Journal of Personality and Social Psychology, 51, 1173-1182.

Berg, J., Dickhaut, J., \& McCabe, K., (1995). Trust, trustworthiness, and social history. Games and Economic Behavior, 10, 122-142.

Bichieri, C., \& Lev-On, A. (2007). Computer-mediated communication and cooperation in social dilemmas: An experimental analysis. Politics, Philosophy, and Economics, 6, 139-168.

Bohnet, I.,\& Frey, B. S. (1999). Social distance and other-regarding behavior in dictator games:Comment. American Economic Review, 89(1), 335-339.

Brandts, J., \& Charness, G. (2000). Hot and cold decisions and reciprocity in experiments with sequential games. Experimental Economics, 2, 227-238.

Bracht, J., \& Feltovich, N. (2009). Whatever you say, your reputation precedes you: Observation and cheap talk in the trust game. Journal of Public Economics, 93, 1036-1044.

Camerer, C. (2003). Behavioral game theory: Experiments in strategic interaction. Princeton, NJ: University Press, Princeton.

Cason, T. \& Mui, V. (1998). Social influence in the sequential dictator game. Journal of Mathematical Psychology, 42, 248-265.

Charness, G., \& Dufwenberg, M. (2006). Promises and partnership. Econometrica, 74, 15791601.

Charness, G., \& Dufwenberg, M. (2010). Bare promises: An experiment. Economics Letters, 107, 281-183.

Charness, G., \& Gneezy, U. (2008). What's in a name? Anonymity and social distance in dictator and ultimatum games. Journal of Economic Behavior \& Organization, 68, 29-35. 
Charness, G., Du, N., Yang, C., \& Yao, L. (2013). Promises in contract design. European Economic Review, 64, 194-208.

Chai, S. K., \& Rhee, M. (2010). Confucian capitalism and the paradox of closure and structural holes in East Asian firms. Management and Organization Review, 6(1), 5-29.

Chaudhuri, A. (2009). Experiments in economics: Playing fair with money. Routledge.

Chiao, C. (1982). Guanxi: A preliminary conceptualization. In K. S. Yang \& C. I. Wen (Eds.), The sinicization of social and behavioral science research in China (pp.345-360). Taipei, ROC: Academia Sinica.

ChinaNews. (October 30, 2013). Microfinancing in China. See http://finance.chinanews.com/it/2013/10-30/541716.shtml.

Chen, C. Chen, X., \& Huang, S. (2013). Chinese Guanxi: An integrative review and new directions for future research. Management and Organization Review. 9(1), 167-207.

Cohen, J., Cohen, P., West, S. \& Aiken, L. (2003). Applied multiple regression /correlation analysis for the behavioral sciences. London: Lawrence Erlbaum Associates.

CreditEase. (2011). 2011 小微企业调研报告。(2011 - A report on Micro- and SmallEnterprises's Management and Financing). See http://www.creditease.cn/special2011/xwzt/.

Ellingsen, T., \& Johannesson, M. (2004). Promises, threats and fairness. Economic Journal, 114, 397-420.

Farh, J. L., Tsui, A. S., Xin, K., \& Cheng, B. (1998). The influence of relational demography and guanxi: The Chinese case. Organizational Science, 9(4), 471-488.

Fei, X. (2012), Xiangtu Zhongguo. (From the Soil: The Foundations of Chinese Society). Beijing, PRC: Renmin Press.

Gert, B. (1998). Morality: Its Nature and Justification. New York: Oxford University Press.

Hoffman, E., McCabe, K. A. Shachat, K., \& Smith, V. L. (1994). Preferences, property rights, and anonymity in bargaining games. Games and Economic Behavior, 7(3), 346-80.

Jacobs, J. B. (1979). A preliminary model of particularistic ties in Chinese political alliances: Kan-ch'ing and Kuan-hsi in a rural Taiwanese township. The China Quarterly, 78, 237-273.

Johnson, I. (July 4, 2014). An online shift in China muffles an open forum. New York Times.

Johnson, N., \& Mislin, A. (2013). Trust games: A meta-analysis. Journal of Economic Psychology, 32(1), 865-889.

Kachelmeier, S., \& Shehata, M. (1997). Internal auditing and voluntary cooperation in firms: A cross-cultural experiment. The Accounting Review 72, 407-431.

King, A. Y. (1991). Kuan-hsi and network building: A sociological interpretation. Daedalus, 120(2), 63-84.

Luo, Y. D. (2000). Guanxi and business. Singapore: World Scientific Publishing.

Mann, L., Radford, M., \& Kanagawa, C. (1985). Cross-cultural difference in children's use of decision rules: A comparison between Japan and Australia. Journal of Personality and Social Psychology, 49(6), 1557-1564.

Oakley, E. F., \& Lynch, P. (2000). Promise-keeping: A low priority in a hierarchy of workplace values. Journal of Business Ethics, 27, 377-392.

Ostrom, E., Walker, J., \& Gardenr, J. (1992). Covenants with and without the sword: Selfgovernance is possible. American Political Science Review, 86, 404-417.

Qi, X. (2011). Face: A Chinese concept in a global sociology. Journal of Sociology, 47, 279-295.

Roth, A.E., (1995). Bargaining experiments. In J. H. Kagel, \& A. E. Roth (Eds.), Handbook of experimental economics (pp. 253-348). Princeton, NJ: Princeton University Press.

Sally, D. (1995). Conversation and cooperation in social dilemmas: A meta-analysis of 
experiments from 1958 to 1992. Rationality and Society, 7, 58-92.

Schlenker, B. R. (1980). Impression management: The self-concept, social identity, and interpersonal relations. Monterey, CA.: Brooks/Cole.

Schneider, D. J. (1969). Tactical self-presentation after success and failure, Journal of Personality and Social Psychology, 13, 262-68.

Schneider, D. J. (1981). Tactical self-presentations: Toward a broader conception. In J. T.

Tedeschi (Ed.), Impression management theory and social psychological research (pp. 23-40). New York: Academic.

Selten, R. (1967). Die strategie methode zur erforschung des eigeschrankt rationalen verhaltens im rahmen eines oligopolexperiments. In H. Sauermann (Ed.), Beitrage zur experimentellen wirt schaftsforschung (pp. 136-168). Tubingen: J.C.B. Mohr.

Shutte, M. \& Thoma, C. (2014). Promises and image concerns. University of Munich, Department of Economics - Working Paper Series. Munich Discussion Papers No. 2014-18.

Song, F., Cadsby, C. B., \& Bi, Y. (2012). Trust, reciprocity, and guanxi in China: An experimental investigation. Management and Organization Review, 8(2), 397-421.

Su, C., \& Littlefield, J. E. (2001). Entering guanxi: A business ethical dilemma in mainland China? Journal of Business Ethics, 33(3), 199-210.

Tajfel, H., \& Turner, J. C. (1979). An integrative theory of intergroup conflict. In W. G. Austin \& S. Worchel (Eds.), The social psychology of intergroup relations (pp. 33-47). Monterey, CA: Brooks/Cole.

Tsui, A. S., \& Farh, J. L. (1997). Where Guanxi matters: Relational demography and guanxi in the Chinese context. Work and Occupations, 24(1), 56-79.

Tedeschi, J. T., \& M. Riess, (1981). Identities, the phenomenal self, and laboratory research. In J. T. Tedeschi (Ed.), Impression management theory and social psychological research (pp. 322). New York: Academic.

Vanberg, C. (2008). Why do people keep their promises? An experimental test of two explanations. Econometrica, 76(6), 1467-1480.

Xin, K. R., \& Pearce, J. L. (1996). Guanxi: Connections as substitutes for formal institutional support. Academy of Management Journal, 39(6), 1641-1658.

Yang, M. M. (1994). Gifts, favors and banquets: The art of social relationships in China. Ithaca, NY: Cornell University Press. 
Table 1 Summary Statistics: Means and Standard Errors

\begin{tabular}{|c|c|c|c|c|c|c|}
\hline & \multicolumn{4}{|c|}{ Chinese Data } & \multicolumn{2}{|c|}{ New Zealand Data } \\
\hline & $\begin{array}{l}\text { Stranger-NoID } \\
\text { (obs. 400) }\end{array}$ & $\begin{array}{l}\text { Stranger-ID } \\
\text { (obs. 400) }\end{array}$ & $\begin{array}{c}\text { Classmate-NoID } \\
\text { (obs. 400) }\end{array}$ & $\begin{array}{l}\text { Classmate-ID } \\
\text { (obs. 400) }\end{array}$ & $\begin{array}{l}\text { Stranger-NoID } \\
\text { (obs. } 400)\end{array}$ & $\begin{array}{l}\text { Stranger-ID } \\
\text { (obs. 400) }\end{array}$ \\
\hline Proposed Amount to Send & 14.10 & 15.65 & 16.55 & 16.26 & 15.49 & 16.03 \\
\hline & $(4.90)$ & $(5.02)$ & $(5.11)$ & $(4.99)$ & $(4.82)$ & $(4.78)$ \\
\hline Proposed Amount to Return & 25.20 & 29.01 & 31.41 & 30.53 & 28.35 & 28.95 \\
\hline (Y) & $(9.54)$ & $(11.06)$ & $(11.32)$ & $(10.85)$ & $(11.03)$ & $(10.22)$ \\
\hline Proposed Reciprocity Ratio & 1.78 & 1.84 & 1.92 & 1.86 & 1.81 & 1.79 \\
\hline$(\mathrm{Y} / \mathrm{X})^{\mathrm{a}}$ & $(0.01)$ & $(0.02)$ & $(0.05)$ & $(0.01)$ & $(0.02)$ & $(0.01)$ \\
\hline \multirow[t]{2}{*}{ Proportion of Promises Kept } & 0.44 & 0.66 & 0.62 & 0.70 & 0.37 & 0.42 \\
\hline & $(0.50)$ & $(0.48)$ & $(0.49)$ & $(0.46)$ & $(0.48)$ & $(0.49)$ \\
\hline Proportion of Proposals & 0.69 & 0.76 & 0.77 & 0.79 & 0.54 & 0.61 \\
\hline Accepted & $(0.46)$ & $(0.43)$ & $(0.42)$ & $(0.41)$ & $(0.50)$ & $(0.49)$ \\
\hline \multirow[t]{2}{*}{ Actual Amount Sent } & 9.41 & 11.99 & 12.78 & 12.81 & 8.43 & 9.96 \\
\hline & $(7.50)$ & $(8.05)$ & $(8.28)$ & $(7.78)$ & $(8.52)$ & (8.79) \\
\hline Actual Amount Returned for & 17.87 & 26.87 & 25.84 & 27.10 & 14.77 & 18.95 \\
\hline Accepted Proposals & $(0.70)$ & $(0.76)$ & $(0.87)$ & $(0.77)$ & $(0.87)$ & $(0.96)$ \\
\hline Actual Reciprocity Ratio for & 1.27 & 1.62 & 1.52 & 1.58 & 0.94 & 1.17 \\
\hline Accepted Proposals ${ }^{c}$ & $(0.04)$ & $(0.03)$ & $(0.07)$ & $(0.04)$ & $(0.05)$ & $(0.05)$ \\
\hline
\end{tabular}

${ }^{\mathrm{a}}$ This ratio is not defined for the three cases where $\mathrm{X}=0$. Defined observations for this variable are $399,399,399,400,400$, and 400 respectively for the six treatments as outlined above.

${ }^{\mathrm{b}}$ Defined observations for this variable are 277, 303, 308, 317, 217 and 242 respectively for the six treatments as outlined above.

${ }^{c}$ This ratio is not defined for the three cases where $X=0$. Defined observations for this variable are 276, 302, 308, 317, 217 and 242 respectively for the six treatments as outlined above. 
Table 2 Key Independent Variable Definitions and Interpretations

\begin{tabular}{|c|c|c|}
\hline Variable Name & Definition & Interpretation \\
\hline Constant & & $\begin{array}{l}\text { (Baseline: China-Stranger-NoID } \\
\text { treatment in Period 10) }\end{array}$ \\
\hline Period & $\begin{array}{l}\text { Period variable, centered } \\
\text { at period } 10 .\end{array}$ & $\begin{array}{l}\text { Centering at period } 10 \text { implies that } \\
\text { treatment effects are fitted for period } \\
10 \text { in specifications where treatment } \\
\text { effects interact with period. }\end{array}$ \\
\hline $\mathrm{NZ}$ & $\begin{array}{l}1 \text { for both New Zealand } \\
\text { (Stranger) treatments, and } \\
0 \text { otherwise. }\end{array}$ & $\begin{array}{l}\text { Difference between New Zealand- } \\
\text { NoID treatment and China-Stranger- } \\
\text { NoID treatment. }\end{array}$ \\
\hline NZ_ID & $\begin{array}{l}1 \text { for the New Zealand-ID } \\
\text { treatment, and } 0 \text { otherwise. }\end{array}$ & $\begin{array}{l}\text { Difference between New Zealand-ID } \\
\text { treatment and New Zealand-NoID } \\
\text { treatment. }\end{array}$ \\
\hline China_Class & $\begin{array}{l}1 \text { for both China- } \\
\text { Classmate treatments, and } \\
0 \text { otherwise. }\end{array}$ & $\begin{array}{l}\text { Difference between China- } \\
\text { Classmate-NoID treatment and } \\
\text { China- Stranger-NoID treatment. }\end{array}$ \\
\hline China_Class_ID & $\begin{array}{l}1 \text { for the China-Classmate- } \\
\text { ID treatment, and } 0 \\
\text { otherwise. }\end{array}$ & $\begin{array}{l}\text { Difference between China- } \\
\text { Classmate-ID treatment and China- } \\
\text { Classmate-NoID treatment. }\end{array}$ \\
\hline China_Stranger_ID & $\begin{array}{l}1 \text { for the China-Stranger- } \\
\text { ID treatment, and } 0 \\
\text { otherwise. }\end{array}$ & $\begin{array}{l}\text { Difference between China-Stranger- } \\
\text { ID treatment and China-Stranger- } \\
\text { NoID treatment. }\end{array}$ \\
\hline
\end{tabular}


Table 3 Logit Regression Coefficients of Treatment Effects on the Probability of Keeping a Contingent Promise (Random Effect for each Borrower, Standard Errors in Parentheses)

\begin{tabular}{|c|c|c|c|c|}
\hline & Model 1 & Model 2 & Model 3 & Model 4 \\
\hline Constant (Baseline: & $-1.21 * *$ & $-1.28 * *$ & -0.78 & -0.74 \\
\hline China-Stranger-NoID & $(0.63)$ & $(0.59)$ & $(0.84)$ & $(0.81)$ \\
\hline \multicolumn{5}{|l|}{ Treatment) } \\
\hline Period (Centered at & $-0.14 * * *$ & $-0.15 * * *$ & $-0.15 * * *$ & $-0.16 * * *$ \\
\hline the Last Period) & $(0.05)$ & $(0.02)$ & $(0.05)$ & $(0.02)$ \\
\hline \multirow[t]{2}{*}{$\mathrm{NZ}$} & -1.11 & -0.92 & -1.05 & -1.03 \\
\hline & $(0.90)$ & $(0.81)$ & $(0.93)$ & $(0.85)$ \\
\hline \multirow[t]{2}{*}{ NZ_ID } & 1.21 & 0.88 & 1.17 & 0.88 \\
\hline & $(0.90)$ & $(0.82)$ & $(0.94)$ & $(0.85)$ \\
\hline \multirow[t]{2}{*}{ China_Class } & $1.65 *$ & $2.05 * *$ & $2.00 * *$ & $2.34 * * *$ \\
\hline & $(0.89)$ & $(0.82)$ & $(0.94)$ & $(0.87)$ \\
\hline \multirow[t]{2}{*}{ China_Class_ID } & 0.95 & 0.62 & 0.57 & 0.38 \\
\hline & $(0.88)$ & $(0.88)$ & $(0.92)$ & $(0.85)$ \\
\hline \multirow[t]{2}{*}{ China_Stranger_ID } & $2.26 * *$ & $2.15 * * *$ & $2.29 * *$ & $2.20 * * *$ \\
\hline & $(0.89)$ & $(0.89)$ & $(0.92)$ & $(0.85)$ \\
\hline \multirow[t]{2}{*}{ NZ $\times$ Period } & -0.04 & & -0.004 & \\
\hline & $(0.08)$ & & $(0.08)$ & \\
\hline \multirow[t]{2}{*}{ NZ_ID $\times$ Period } & 0.07 & & 0.06 & \\
\hline & $(0.08)$ & & $(0.08)$ & \\
\hline \multirow[t]{2}{*}{ China_Class $\times$ Period } & -0.09 & & -0.07 & \\
\hline & $(0.08)$ & & $(0.08)$ & \\
\hline China_Class_ID $\times$ & 0.08 & & 0.04 & \\
\hline Period & $(0.08)$ & & $(0.08)$ & \\
\hline China_Stranger_ID $\times$ & 0.03 & & 0.02 & \\
\hline Period & $(0.08)$ & & $(0.08)$ & \\
\hline Proposed Amount to & & & $0.07 * * *$ & $0.07 * * *$ \\
\hline Send $(X)$ & & & $(0.02)$ & $(0.02)$ \\
\hline Proposed Reciprocity & & & $-0.89 * * *$ & $-0.90 * * *$ \\
\hline Ratio (Y/X) & & & $(0.23)$ & $(0.23)$ \\
\hline Observations & 2400 & 2400 & 2397 & 2397 \\
\hline Log Likelihood & -999.01 & -1000.67 & -980.45 & -981.92 \\
\hline Wald chi-square & 73.02 & 70.86 & 92.42 & 90.32 \\
\hline
\end{tabular}

Notes: $* * * p<0.01, * * p<0.05, * p<0.1$. All tests are two-tailed. 
Table 4 Logit Regression Coefficients of Treatment Effects on the Probability of Accepting a Proposal (Random Effects for each Investor, Standard Errors in Parentheses)

\begin{tabular}{|c|c|c|}
\hline & Model 1 & Model 2 \\
\hline Constant (Baseline: China-Stranger-NoID & $0.56^{*}$ & $-2.32 * * *$ \\
\hline Treatment) & $(0.32)$ & $(0.49)$ \\
\hline Period (Centered at the Last Period) & $\begin{array}{c}-0.11 * * * \\
(0.04)\end{array}$ & $\begin{array}{c}-0.13 * * * \\
(0.04)\end{array}$ \\
\hline NZ & $\begin{array}{c}-1.02 * * \\
(0.45)\end{array}$ & $\begin{array}{c}-0.96 * * \\
(0.43)\end{array}$ \\
\hline NZ_ID & $\begin{array}{c}0.68 \\
(0.45)\end{array}$ & $\begin{array}{l}0.73^{*} \\
(0.43)\end{array}$ \\
\hline China_Class & $\begin{array}{l}1.20 * * \\
(0.47)\end{array}$ & $\begin{array}{c}0.72 \\
(0.45)\end{array}$ \\
\hline China_Class_ID & $\begin{array}{c}0.20 \\
(0.50)\end{array}$ & $\begin{array}{c}0.36 \\
(0.48)\end{array}$ \\
\hline China_Stranger_ID & $\begin{array}{l}0.88^{*} \\
(0.46)\end{array}$ & $\begin{array}{c}0.53 \\
(0.44)\end{array}$ \\
\hline $\mathrm{NZ} \times$ Period & $\begin{array}{l}-0.05 \\
(0.06)\end{array}$ & $\begin{array}{l}-0.06 \\
(0.08)\end{array}$ \\
\hline NZ_ID $\times$ Period & $\begin{array}{c}0.08 \\
(0.06)\end{array}$ & $\begin{array}{c}0.07 \\
(0.06)\end{array}$ \\
\hline China_Class $\times$ Period & $\begin{array}{l}0.12 * \\
(0.06)\end{array}$ & $\begin{array}{c}0.07 \\
(0.06)\end{array}$ \\
\hline China_Class_ID $\times$ Period & $\begin{array}{c}0.04 \\
(0.07)\end{array}$ & $\begin{array}{c}0.06 \\
(0.06)\end{array}$ \\
\hline China_Stranger_ID $\times$ Period & $\begin{array}{c}0.07 \\
(0.06)\end{array}$ & $\begin{array}{c}0.06 \\
(0.07)\end{array}$ \\
\hline Proposed Amount to Send (X) & & $\begin{array}{c}-0.03 * * * \\
(0.01)\end{array}$ \\
\hline Proposed Reciprocity Ratio (Y/X) & & $\begin{array}{c}1.63 * * * \\
(0.21)\end{array}$ \\
\hline Previous Observed Promise-Keeping Rate & & $\begin{array}{c}1.25 * * * \\
(0.24)\end{array}$ \\
\hline Observations & 2400 & 2271 \\
\hline Log Likelihood & -1273.41 & -1146.79 \\
\hline Wald chi-square & 55.03 & 137.62 \\
\hline
\end{tabular}

Notes: $* * * p<0.01, * * p<0.05, * p<0.1$. All tests are two-tailed. 
Table 5 Regression Coefficients of Treatment Effects on Proposed Amount to Send (X) and Proposed Reciprocity Ratio (Y/X) (Random Effect for each Borrower, Standard Errors in Parentheses)

\begin{tabular}{|c|c|c|c|}
\hline & \multirow{2}{*}{$\begin{array}{l}\text { Proposed } \\
\text { Amount to } \\
\text { Send (X) }\end{array}$} & \multicolumn{2}{|c|}{$\begin{array}{l}\text { Proposed Reciprocity Ratio } \\
\text { (Y/X) }\end{array}$} \\
\hline & & Model 1 & Model 2 \\
\hline Constant (Baseline: & $14.98 * * *$ & $1.79 * * *$ & $1.82^{* * * *}$ \\
\hline $\begin{array}{l}\text { China-Stranger- } \\
\text { NoID Treatment) }\end{array}$ & $(0.68)$ & $(0.05)$ & $(0.04)$ \\
\hline $\begin{array}{l}\text { Period (Centered at } \\
\text { the Last Period) }\end{array}$ & $\begin{array}{c}0.20^{* * * *} \\
(0.05)\end{array}$ & $\begin{array}{l}0.0008 \\
(0.007)\end{array}$ & $\begin{array}{c}0.008^{* * * *} \\
(0.003)\end{array}$ \\
\hline $\mathrm{NZ}$ & $\begin{array}{l}-0.38 \\
(0.96)\end{array}$ & $\begin{array}{c}0.05 \\
(0.07)\end{array}$ & $\begin{array}{c}0.03 \\
(0.06)\end{array}$ \\
\hline NZ_ID & $\begin{array}{l}1.17 \\
(0.96)\end{array}$ & $\begin{array}{c}0.01 \\
(0.07)\end{array}$ & $\begin{array}{l}-0.02 \\
(0.07)\end{array}$ \\
\hline China_Class & $\begin{array}{l}2.05 * * \\
(0.96)\end{array}$ & $\begin{array}{c}0.21 * * * \\
(0.07)\end{array}$ & $\begin{array}{c}0.14 * * \\
(0.06)\end{array}$ \\
\hline China_Class_ID & $\begin{array}{c}1.06 \\
(0.96)\end{array}$ & $\begin{array}{l}-0.12^{*} \\
(0.07)\end{array}$ & $\begin{array}{l}-0.06 \\
(0.06)\end{array}$ \\
\hline China_Stranger_ID & $\begin{array}{l}1.61^{*} \\
(0.96)\end{array}$ & $\begin{array}{c}0.09 \\
(0.07)\end{array}$ & $\begin{array}{c}0.06 \\
(0.06)\end{array}$ \\
\hline $\mathrm{NZ} \times$ Period & $\begin{array}{c}-0.39 * * * \\
(0.07)\end{array}$ & $\begin{array}{c}0.01 \\
(0.07)\end{array}$ & \\
\hline NZ_ID $\times$ Period & $\begin{array}{l}0.14^{*} \\
(0.07)\end{array}$ & $\begin{array}{c}0.01 \\
(0.01)\end{array}$ & \\
\hline China_Class $\times$ & -0.09 & $0.02 *$ & \\
\hline Period & $(0.07)$ & $(0.01)$ & \\
\hline China_Class_ID $\times$ & $0.30^{* * *}$ & -0.01 & \\
\hline Period & $(0.07)$ & $(0.01)$ & \\
\hline $\begin{array}{l}\text { China_Stranger_ID } \\
\times \text { Period }\end{array}$ & $\begin{array}{c}0.01 \\
(0.07)\end{array}$ & $\begin{array}{c}0.01 \\
(0.01)\end{array}$ & \\
\hline Observations & 2400 & 2397 & 2397 \\
\hline Wald chi-square & 122.06 & 19.31 & 15.79 \\
\hline
\end{tabular}


Table 6 Negative Binomial Regression Coefficients and Incidence Rate Ratios (IRRs) of Treatment Effects on the Number of Promises Kept for Accepted Proposals over all 10 Periods (Errors clustered for each session)

\begin{tabular}{lccc}
\hline & Coefficient & Std. Error & IRR \\
\hline Constant (Baseline: China- & $-0.84 * * *$ & 0.15 & $0.43^{* * *}$ \\
Stranger-NoID Treatment) & & & \\
NZ & -0.20 & 0.19 & 0.82 \\
NZ_ID & 0.21 & 0.14 & 1.24 \\
China_Class & $0.41^{* *}$ & 0.20 & $1.51 * *$ \\
China_Class_ID & 0.07 & 0.15 & 1.08 \\
China_Stranger_ID & $0.47^{* * *}$ & 0.17 & $1.60 * * *$ \\
\hline
\end{tabular}

Observations: 237 (Three lenders did not accept any proposals.)

Log Pseudo-Likelihood: -396.71

Wald chi-square: 62.71

Notes: $* * * p<0.01, * * p<0.05, * p<0.1$. All tests are two-tailed. 
Table 7 Regression Coefficients of Treatment Effects on Actual Amount Sent by Investors (Cross Random Effects for each Investor and Borrower, Standard Errors in Parentheses)

\begin{tabular}{lc}
\hline & Actual Amount Sent \\
\hline Constant (Baseline: China- & $8.88^{* * *}$ \\
Stranger-NoID Treatment) & $(0.95)$ \\
Period & -0.12 \\
(Centered at the Last Period) & $(0.11)$ \\
NZ & $-3.13^{* *}$ \\
& $(1.34)$ \\
NZ_ID & $3.15^{* *}$ \\
& $(1.34)$ \\
China_Class & $4.39^{* * *}$ \\
& $(1.34)$ \\
China_Class_ID & 1.84 \\
& $(1.34)$ \\
China_Stranger_ID & $3.80^{* * *}$ \\
& $(1.34)$ \\
NZ $\times$ Period & $-0.48^{* * *}$ \\
& $(0.16)$ \\
NZ_ID $\times$ Period & $0.36^{* *}$ \\
& $(0.16)$ \\
China_Class $\times$ Period & 0.23 \\
& $(0.16)$ \\
China_Class_ID $\times$ Period & $0.40^{* *}$ \\
& $(0.16)$ \\
China_Stranger_ID $\times$ Period & $0.27 *$ \\
& $(0.16)$ \\
\hline Observations & 2400 \\
Log Likelihood & -8185.60 \\
Wald chi-square & 82.79 \\
\hline Notes: $* * * p<0.01, * * p<0.05, * p<0.1$. All tests are two-tailed.
\end{tabular}


Figure 1 Proportion of Promises Kept over Time in the Six Treatments

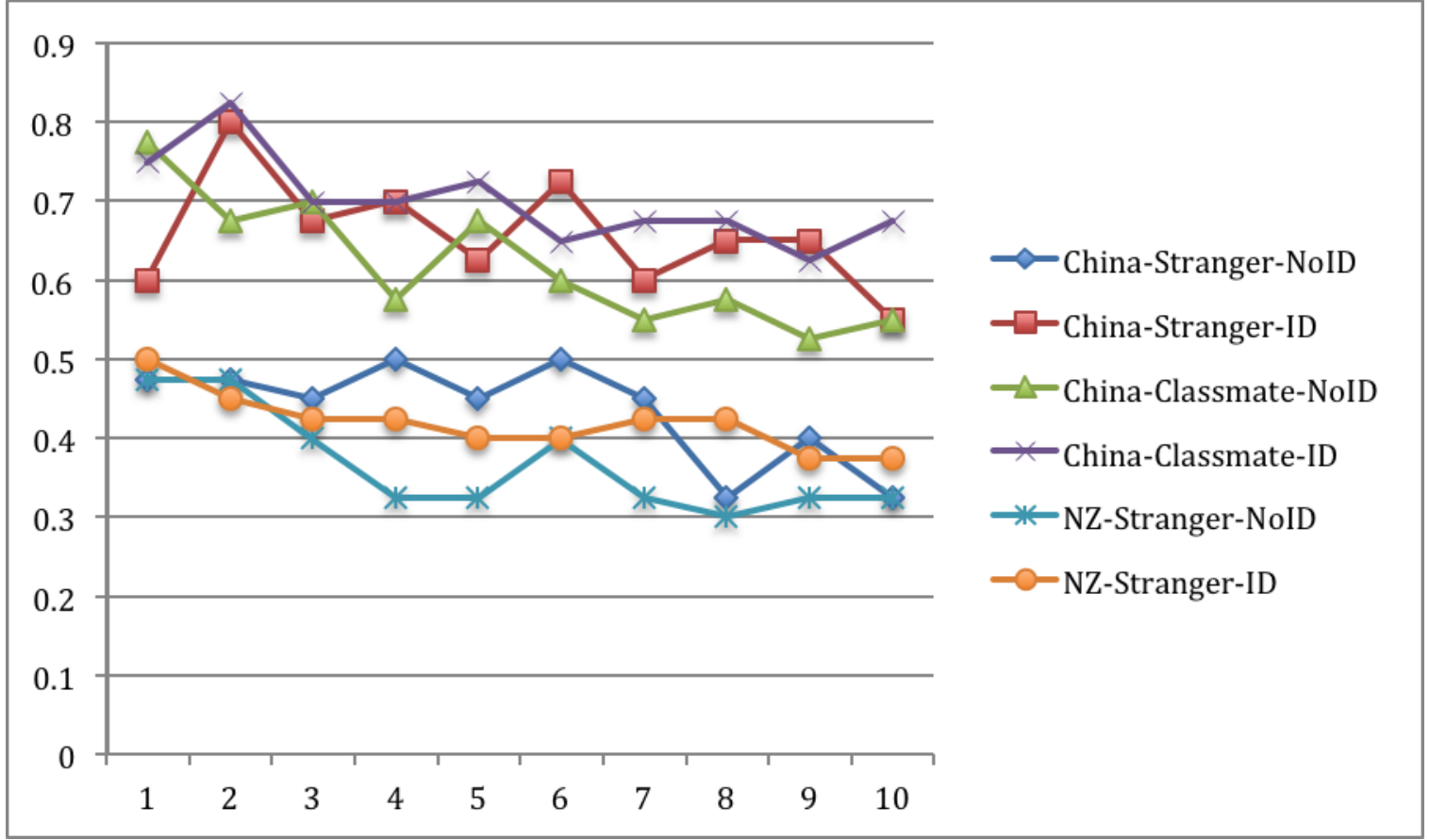

Figure 2 Proportion of Proposals Accepted over Time in the Six Treatments

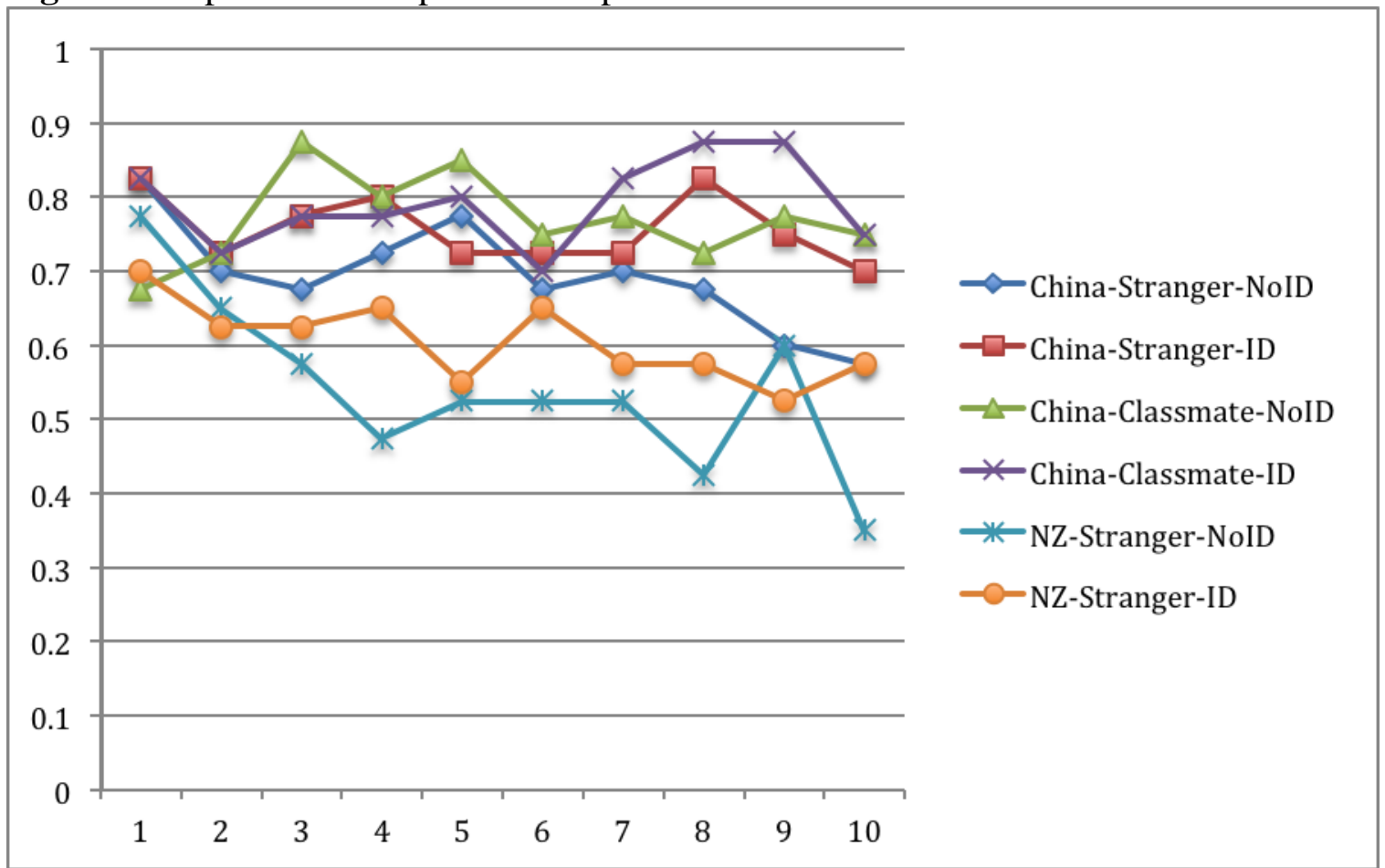


Figure 3 Actual Amount Sent by Investors over Time in the Six Treatments

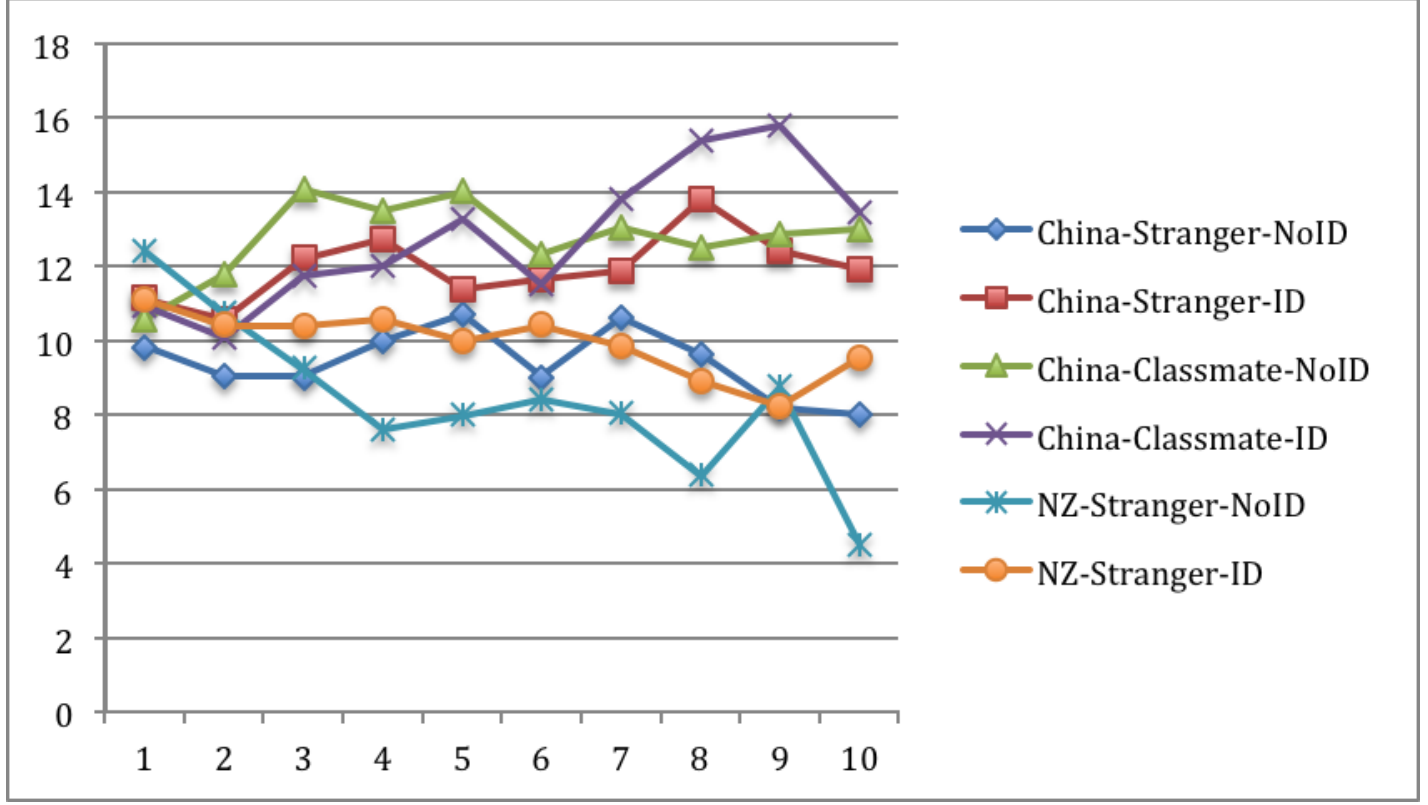

